\title{
ARTICLE
}

\section{Direct synthesis of formic acid from carbon dioxide by hydrogenation in acidic media}

Séverine Moret ${ }^{1}$ Paul J. Dyson ${ }^{1} \&$ Gábor Laurenczy ${ }^{1}$

The chemical transformation of carbon dioxide into useful products becomes increasingly important as $\mathrm{CO}_{2}$ levels in the atmosphere continue to rise as a consequence of human activities. In this article we describe the direct hydrogenation of $\mathrm{CO}_{2}$ into formic acid using a homogeneous ruthenium catalyst, in aqueous solution and in dimethyl sulphoxide (DMSO), without any additives. In water, at $40^{\circ} \mathrm{C}, 0.2 \mathrm{M}$ formic acid can be obtained under 200 bar, however, in DMSO the same catalyst affords $1.9 \mathrm{M}$ formic acid. In both solvents the catalysts can be reused multiple times without a decrease in activity. Worldwide demand for formic acid continues to grow, especially in the context of a renewable energy hydrogen carrier, and its production from $\mathrm{CO}_{2}$ without base, via the direct catalytic carbon dioxide hydrogenation, is considerably more sustainable than the existing routes.

\footnotetext{
${ }^{1}$ Institut des Sciences et Ingénierie Chimiques, Ecole Polytechnique Fédérale de Lausanne (EPFL), CH-1015 Lausanne, Switzerland. Correspondence and requests for materials should be addressed to G.L. (email: gabor.laurenczy@epfl.ch).
} 
C oncerns over carbon dioxide levels in the atmosphere, which have reached ca. 400 p.p.m. ${ }^{1,2}$, are leading to political targets and scientific/technological efforts to reduce $\mathrm{CO}_{2}$ emissions and to capture $\mathrm{CO}_{2}$ and store it within porous rock formations ${ }^{3-6}$. Converting $\mathrm{CO}_{2}$ into useful feedstock chemicals and fuels represents another important strategy that not only removes $\mathrm{CO}_{2}$ from the atmosphere, but also reduces dependence on petrochemicals ${ }^{7,8}$. In this context much progress has been made in recent years and several reactions have been commercialized. Examples of products now derived from $\mathrm{CO}_{2}$ include urea, salicylic acid and polyols ${ }^{3}$. Recently, a company in Iceland started using renewable energy to convert $\mathrm{CO}_{2}$ into methanol, in the region of $1,600 \mathrm{~T}$ per year ${ }^{9}$. However, human activity contributes $\sim 35 \mathrm{GT}$ of $\mathrm{CO}_{2}$ to the atmosphere per year and there is clearly a considerable gap between the amount of $\mathrm{CO}_{2}$ produced and the amount consumed.

Ideally a multitude of chemical products should be derived from $\mathrm{CO}_{2}$ (ref. 10) and an important one, as it may be employed as both a feedstock chemical and a fuel, is formic acid. Currently worldwide production of formic acid, obtained from the combination of methanol and carbon monoxide with a strong base, is in the order of $800,000 \mathrm{~T}$ per year and is used in the textile industry, cleaning and as a preservative, to name a few. Demand could increase considerably due to the development of efficient formic acid dehydrogenation catalysts that could find widespread application within the context of a hydrogen economy ${ }^{11}$. Today, with the exception of fossil fuels, practical hydrogen storage systems use pressurized bottles or cryogenic conditions ${ }^{12}$. As formic acid $(\mathrm{HCOOH})$ has a volumetric hydrogen density of $53 \mathrm{~g}$ of $\mathrm{H}_{2}$ per liter, a low-toxicity and is a liquid under ambient conditions, it is an ideal hydrogen storage material for certain applications ${ }^{13,14}$. Hydrogen production from formic acid has been achieved with a variety of homogeneous and heterogeneous catalysts ${ }^{15,16}$. Although most catalysts are based on noble metals, recent complexes based on iron (a cheap and abundant element) highlight the validity of such systems within the context of a hydrogen economy ${ }^{17}$. The concept of the hydrogen storage in the form of formic acid would, however, be even more attractive should a viable catalyst for the reverse reaction become available, that is, a catalyst that reduces carbon dioxide with hydrogen and in the absence of a base ${ }^{18-22}$ (Fig. 1).

Several catalysts are available for both reactions, and in general, hydrogen production or consumption is controlled by the $\mathrm{pH}$ of the solution ${ }^{23-26}$. However, the conversion of carbon dioxide into formic acid is difficult owing to the high kinetic and thermodynamic stability of $\mathrm{CO}_{2}$. The gas phase reaction has a positive $\Delta \mathrm{G}$ value because of an entropic contribution $\left(\Delta \mathrm{G}^{0}=+33 \mathrm{KJ} \mathrm{mol}^{-1}\right)$, and the formation of formic acid is more favourable in aqueous solution $\left(\Delta \mathrm{G}^{0}=-4 \mathrm{KJ} \mathrm{mol}^{-1}\right.$ ) (ref. 20). For reactions performed in water, the $\mathrm{CO}_{2} / \mathrm{H}_{2} \mathrm{CO}_{3} / \mathrm{HCO}_{3}^{-}$ equilibrium, as well as the second deprotonation to $\mathrm{CO}_{3}^{2}-$, must be taken into account (Supplementary Fig. 1). From these equilibria and the kinetic studies performed on the hydrogenation of bicarbonates at different $\mathrm{pH}$ values ${ }^{27}$ it is apparent that the reaction is favourable in basic media, conditions where the actual substrate is $\mathrm{HCO}_{3}^{-}\left(\Delta \mathrm{G}^{0}=-35 \mathrm{KJ} \mathrm{mol}^{-1}\right)$ or $\mathrm{CO}_{3}^{2-}$.

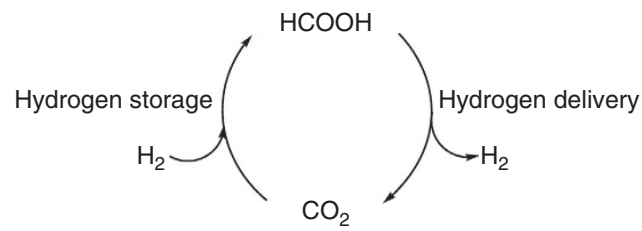

Figure 1 | The formic acid/carbon dioxide cycle for hydrogen storage.
In contrast to the direct reaction of $\mathrm{H}_{2}$ with $\mathrm{CO}_{2}$, the hydrogenation of carbonate and bicarbonate are well-established reactions ${ }^{28-30}$ that have been achieved in a wide variety of organic solvents, ionic liquids, water and supercritical $\mathrm{CO}_{2}$ (ref. 20). Currently, catalysts that show high activity in the hydrogenation of $\mathrm{CO}_{2}$ require additives such as bases ${ }^{31,32}$, including amines ${ }^{33}$ or buffers ${ }^{34,35}$, producing formate salts. Ogo et al. ${ }^{34,35}$ were able to produce formic acid $(0.06 \mathrm{M})$ from the direct reaction of $\mathrm{H}_{2}$ with $\mathrm{CO}_{2}$ in an acidic buffer. The presence of base also complicates the separation of formic acid from the reaction mixture although ingenious approaches have been developed to overcome these complications ${ }^{30,36}$. Herein, we describe a homogeneous ruthenium catalyst that hydrogenates $\mathrm{CO}_{2}$ to formic acid in acidic media, without the need of any bases, amines or buffers. In aqueous solution, $0.2 \mathrm{M}$ formic acid can be obtained, in dimethyl sulphoxide (DMSO) the ruthenium(II) phosphine catalyst provides $1.9 \mathrm{M}$ formic acid.

\section{Results}

Direct carbon dioxide hydrogenation in water. In our initial studies the hydrogenation of $\mathrm{CO}_{2}$ was explored in acidic aqueous solutions using ruthenium(II) or rhodium(I) catalysts with water soluble phosphine ligands, that is, 1,3,5-triaza-7phosphaadamantane (PTA), 3-methyl-1,3,5- triaza-7-phosphaadamantane (MePTA), meta-monosulphonated triphenylphosphine (TPPMS) and meta-trisulphonated triphenylphosphine (TPPTS; Supplementary Table 1). From these studies $\left[\mathrm{RuCl}_{2}(\mathrm{PTA})_{4}\right]$ was found to be the most active catalyst affording formic acid as the only product under the reaction conditions (at the end of the reaction the $\mathrm{pH}$ of the solution is 2.70 , Fig. 2 and Supplementary Fig. 2). The ruthenium catalysts were typically 10 times more active than the rhodium analogues and the highest yields were obtained for complexes containing PTA-type ligands, that is, similar activities were observed for the PTA and MePTA ligands, whereas complexes with TPPMS and TPPTS were less

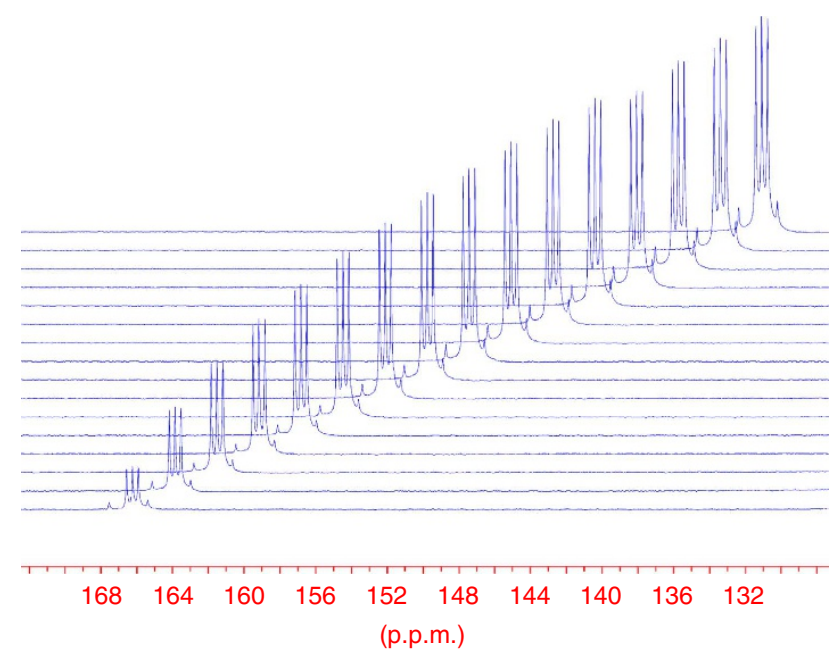

Figure $2 \mid{ }^{13} \mathrm{C}$ NMR signals of DCCOOD in the hydrogenation reactions of $\mathbf{C O}_{\mathbf{2}}$ into formic acid in $\mathbf{D}_{\mathbf{2}} \mathbf{O}$. $\left[\mathrm{RuCl}{ }_{2}(\mathrm{PTA})_{4}\right](2.76 \mathrm{mM})$ was dissolved in $\mathrm{D}_{2} \mathrm{O}(2 \mathrm{ml})$ under $\mathrm{N}_{2}$ atmosphere in a medium pressure sapphire NMR tube. This solution was pressurized at room temperature to 50 bar with $\mathrm{CO}_{2}$ and completed to 100 bar with $\mathrm{H}_{2}$. The system was heated to $60^{\circ} \mathrm{C}$ and the reaction was followed by ${ }^{13} \mathrm{C}$ NMR $(100 \mathrm{MHz})$ spectroscopy. The figure shows the evolution of the ${ }^{13} \mathrm{C}$ NMR signals of DCOOD at 166.3 p.p.m. (time difference between spectra $\Delta t=189 \mathrm{~min}$ ). The triplet signal of the formic acid is due to the exchange of the hydrogen to deuterium in $\mathrm{HCOOH}$ (as $\mathrm{D}_{2} \mathrm{O}$ was used as solvent). Reaction time: $148 \mathrm{~h}$. 
Table 1 | Formic acid formation as function of the catalyst concentration (conc.), pressure and $P\left(\mathrm{H}_{2}\right) / P\left(\mathrm{CO}_{2}\right)$ ratio*.

\begin{tabular}{|c|c|c|c|c|c|}
\hline Entry & Catalyst conc. (M) & Pressure (bar) & $P\left(\mathrm{H}_{2}\right) / P\left(\mathrm{CO}_{2}\right)$ & $\mathrm{HCOOH}^{\dagger}$ (M) & TON $\ddagger$ \\
\hline 1 & 0.00276 & 60 & 1 & 0.030 & 11 \\
\hline 2 & 0.00276 & 70 & 1 & 0.042 & 15 \\
\hline 3 & 0.00276 & 80 & 1 & 0.047 & 17 \\
\hline 4 & 0.00276 & 100 & 1 & 0.083 & 30 \\
\hline 5 & 0.00276 & 100 & 2.3 & 0.086 & 31 \\
\hline 6 & 0.00276 & 100 & 4 & 0.070 & 25 \\
\hline 7 & 0.00276 & 120 & 1.5 & 0.095 & 34 \\
\hline 8 & 0.00276 & 150 & 2 & 0.124 & 45 \\
\hline 9 & 0.00276 & 200 & 3 & 0.204 & 74 \\
\hline 10 & 0.00063 & 100 & 1 & 0.100 & 159 \\
\hline 11 & 0.00546 & 100 & 1 & 0.070 & 13 \\
\hline 12 & 0.00063 & 60 & 1 & 0.035 & 56 \\
\hline 13 & 0.00546 & 60 & 1 & 0.029 & 5 \\
\hline
\end{tabular}

${ }^{*}\left[\mathrm{RuCl}_{2}(\mathrm{PTA})_{4}\right]$ was dissolved in $\mathrm{H}_{2} \mathrm{O}(2 \mathrm{ml})$ under $\mathrm{N}_{2}$ atmosphere. This solution was pressurized at room temperature under $\mathrm{CO}_{2}$ followed by $\mathrm{H}_{2}$ to the required pressure. The system was heated at $60^{\circ} \mathrm{C}$ and stirred until the equilibrium of the reaction was reached (48-84h). The final yield of formic acid was determined by ${ }^{1} \mathrm{H}$ NMR spectroscopy with DSS (DSS, 4,4-dimethyl-4-silapentane-1sulphonic acid) as an internal standard.

$\dagger$ Average values from three to six measurements with a reproducibility of $\pm 15 \%$

$\ddagger$ Turn over number (TON), that is, the number of moles of $\mathrm{CO}_{2}\left(\right.$ or $\left.\mathrm{H}_{2}\right)$ that one mole of catalyst converts into $\mathrm{HCOOH}$.

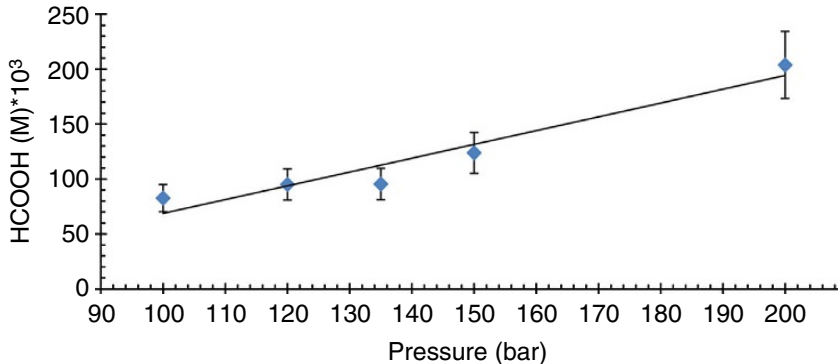

Figure 3 | Pressure dependence on the concentration of formic acid obtained in the catalytic hydrogenation of $\mathbf{C O}_{\mathbf{2}}$. Conditions: the catalyst was dissolved in $2 \mathrm{ml} \mathrm{H}_{2} \mathrm{O}\left(\left[\mathrm{RuCl}_{2}(\mathrm{PTA})_{4}\right]=2.76 \mathrm{mM}\right)$ under $\mathrm{N}_{2}$ atmosphere. This solution was pressurized at room temperature with $\mathrm{CO}_{2}$ (50 bar) and completed with $\mathrm{H}_{2}$ to the desired pressure. The system was heated at $60^{\circ} \mathrm{C}$ and stirred until the equilibrium of the reaction was reached $(72-96 \mathrm{~h})$. The final yield of formic acid was determined by ${ }^{1} \mathrm{H}$ NMR spectroscopy with DSS as an internal standard. The values are averaged from three to six measurements with a reproducibility of $\pm 15 \%$. The trend line is shown as a guide and is not a mathematical fit of the data.

active. The reaction conditions were optimized for $\left[\mathrm{RuCl}_{2}(\mathrm{PTA})_{4}\right]$ to improve performance and the dependence of the catalyst concentration, pressure, $P\left(\mathrm{H}_{2}\right) / P\left(\mathrm{CO}_{2}\right)$ ratio (Table 1) and temperature (Supplementary Table 2 ) on formic acid production was elucidated.

Under relatively mild conditions $\left(60^{\circ} \mathrm{C}, 30\right.$ bar $\mathrm{CO}_{2}, 30$ bar $\mathrm{H}_{2}$, $2.76 \mathrm{mM}$ catalyst $),\left[\mathrm{RuCl}_{2}(\mathrm{PTA})_{4}\right]$ hydrogenates $\mathrm{CO}_{2}$ to afford a $0.03 \mathrm{M}$ formic acid solution. The concentration of formic acid produced depends on the gas pressure. With a $P\left(\mathrm{H}_{2}\right) / P\left(\mathrm{CO}_{2}\right)$ ratio of 1 increasing the total gas pressure from 60 bar to 100 bar affords a $0.083 \mathrm{M}$ formic acid solution (Table 1 ), and at a total gas pressure of 200 bar the concentration of formic acid obtained is $0.204 \mathrm{M}$ (Fig. 3).

The reaction was also studied at temperatures ranging from 23 to $90^{\circ} \mathrm{C}$ under standard conditions $\left(\left[\mathrm{RuCl}_{2}(\mathrm{PTA})_{4}\right]=2.76 \mathrm{mM}\right.$, total pressure $=100$ bar and $P\left(\mathrm{H}_{2}\right) / P\left(\mathrm{CO}_{2}\right)$ pressure ratio $=1$, see Fig. 4 and Supplementary Fig. 3 and Supplementary Table 2). As the hydrogenation of $\mathrm{CO}_{2}$ is exothermic, increasing temperature reduces the final formic acid concentration, which decreases to $0.032 \mathrm{M}$ at $90^{\circ} \mathrm{C}$. The temperature dependence of the reaction rate follows the Arrhenius law from which activation enthalpy of $+96 \mathrm{~kJ} \mathrm{~mol}^{-1}$ was obtained (Supplementary Fig. 4).

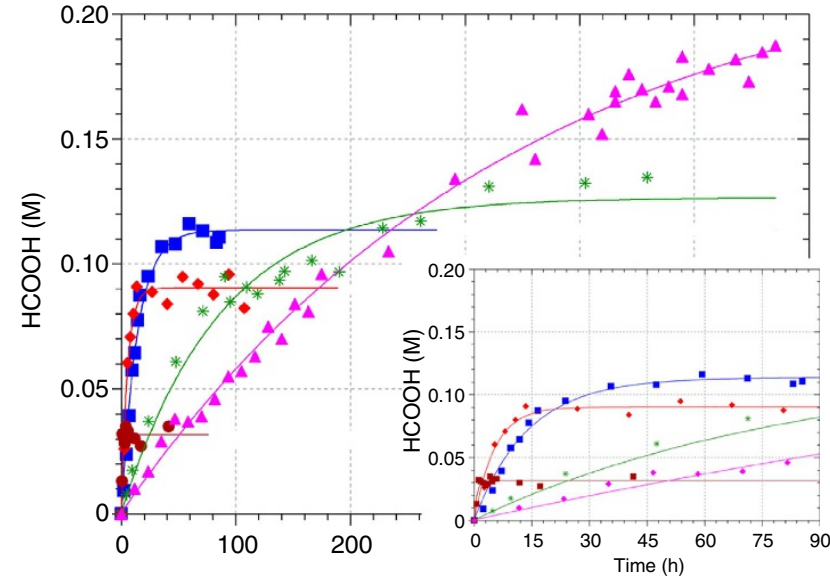

Figure 4 | Influence of temperature on the hydrogenation of $\mathrm{CO}_{2}$ to formic acid using $\left[\mathrm{RuCl}_{2}(\mathrm{PTA})_{4}\right]$ as the catalyst: $90^{\circ} \mathrm{C}$ (brown circle), $60^{\circ} \mathrm{C}$ (red diamond), $50^{\circ} \mathrm{C}$ (blue square), $40^{\circ} \mathrm{C}$ (green asterisk) and $30{ }^{\circ} \mathbf{C}$ (pink triangle). Conditions: $\left[\mathrm{RuCl}_{2}(\mathrm{PTA})_{4}\right]$ was dissolved in $\mathrm{H}_{2} \mathrm{O}$ $(2.76 \mathrm{mM}, 2 \mathrm{ml})$, under $\mathrm{N}_{2}$ atmosphere. The solution was pressurized at room temperature with $\mathrm{CO}_{2}$ (50 bar) and completed with $\mathrm{H}_{2}$ to 100 bar. The system was heated to the desired temperature and the reaction was monitored by ${ }^{1} \mathrm{H}$ NMR spectroscopy until the equilibrium of the reaction was reached. The values are averaged from three to six measurements with a reproducibility of $\pm 15 \%$.

Using the optimized catalytic system, recycling experiments were performed and it was found that the catalyst could be reused without the loss of activity (Supplementary Table 3).

Carbon dioxide hydrogenation in other solvents. As $\left[\mathrm{RuCl}_{2}(\mathrm{PTA})_{4}\right]$ is able to directly hydrogenate carbon dioxide in aqueous acidic solution, that is, at $\mathrm{pH}=2.70$, further studies were performed in water-miscible ionic liquids, that is, 1-butyl-3methylimidazolium terafluoroborate $\left([\mathrm{BMIM}]\left[\mathrm{BF}_{4}\right]\right)$ and 1-butyl3-methylimidazolium tosylate ([BMIM][tos] where tos $=$ the $p-\mathrm{CH}_{3} \mathrm{C}_{6} \mathrm{H}_{4} \mathrm{SO}_{3}^{-}$anion), and in tetrahydrofuran and DMSO (Table 2).

High activities were observed in $\mathrm{DMSO} / \mathrm{H}_{2} \mathrm{O}$ with the catalytic activity increasing as the water/solvent ratio was decreased. 
Table 2 | Catalytic hydrogenation of carbon dioxide to formic acid in different solvent mixtures.

\begin{tabular}{|c|c|c|c|c|c|}
\hline Entry & Solvent & $\mathrm{H}_{2} \mathrm{O}(\%)$ & Solvent (\%) & HCOOH (M) & TON \\
\hline 1 & $\mathrm{H}_{2} \mathrm{O}$ & 100 & - & 0.11 & 40 \\
\hline 2 & {$[\mathrm{BMIM}]\left[\mathrm{BF}_{4}\right]$} & 50 & 50 & 0.15 & 54 \\
\hline 3 & [BMIM][tos] & 52 & 48 & 0.19 & 69 \\
\hline 4 & [BMIM][tos] & 40 & 60 & 0.10 & 36 \\
\hline 5 & {$[\mathrm{BMIM}]\left[\mathrm{BF}_{4}\right]$} & 20 & 80 & 0.14 & 51 \\
\hline 6 & {$[\mathrm{BMIM}]\left[\mathrm{BF}_{4}\right]$} & 10 & 90 & 0.12 & 43 \\
\hline 7 & THF & 50 & 50 & 0.095 & 34 \\
\hline 8 & DMSO & 50 & 50 & 0.34 & 123 \\
\hline 9 & DMSO & 20 & 80 & 0.98 & 355 \\
\hline 10 & DMSO & 10 & 90 & 1.31 & 475 \\
\hline
\end{tabular}

THF, tetrahydrofuran.

Reaction conditions: $\left[\mathrm{RuCl}_{2}(\mathrm{PTA})_{4}\right](2.76 \mathrm{mM}), P($ total $)=100$ bar, $P\left(\mathrm{H}_{2}\right) / P\left(\mathrm{CO}_{2}\right)$ ratio of $1, t=50^{\circ} \mathrm{C}$, reaction time $120 \mathrm{~h}$, solvent ( $2 \mathrm{ml}$ containing DSS, $0.0130 \mathrm{M}$ ), average values of several (two to three) measurements for each cycle, reproducibility is $\pm 15 \%$.

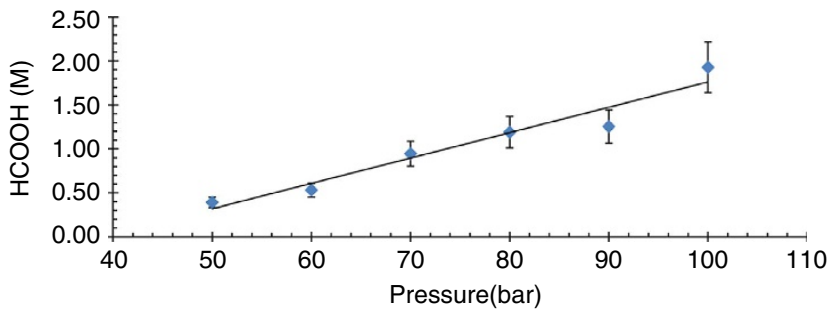

Figure 5 | Pressure effect on the formic acid yield using $\left[\mathrm{RuCl}_{2}(\mathrm{PTA})_{4}\right]$ catalyst in DMSO. Reaction conditions: $\left[\mathrm{RuCl}_{2}(\mathrm{PTA})_{4}\right](2.76 \mathrm{mM})$, $t=50^{\circ} \mathrm{C}, P\left(\mathrm{H}_{2}\right) / P\left(\mathrm{CO}_{2}\right)$ ratio of 1 , reaction time $120 \mathrm{~h}$, DMSO $(2 \mathrm{ml})$, average values of several (two to six) measurements. The trend line is shown as a guide and is not a mathematical fit of the data.

In pure DMSO at $50^{\circ} \mathrm{C}$, a $1.93 \mathrm{M}$ formic acid solution was obtained at 100 bar with a $P\left(\mathrm{H}_{2}\right) / P\left(\mathrm{CO}_{2}\right)$ ratio of 1 . Extensive investigations on the activity of $\left[\mathrm{RuCl}_{2}(\mathrm{PTA})_{4}\right]$ in pure organic solvents, that is, alcohols, acetonitrile, propylene carbonate and toluene (Supplementary Table 4), revealed that the catalyst is active in several solvents, although none were as effective as DMSO. Further screening of other catalysts in DMSO (Supplementary Table 5) confirmed the superiority of $\left[\mathrm{RuCl}_{2}(\mathrm{PTA})_{4}\right]$ in the hydrogenation of $\mathrm{CO}_{2}$, that is, $\left[\mathrm{RuCl}_{2}(\mathrm{PTA})_{4}\right]$ is $\sim 20$ times more active in DMSO compared with the other catalysts evaluated. Hence, the efficiency of $\left[\mathrm{RuCl}_{2}(\mathrm{PTA})_{4}\right]$ in DMSO was studied as a function of the total gas pressure (Fig. 5 and Supplementary Table 6) and the $\mathrm{P}\left(\mathrm{H}_{2}\right) / \mathrm{P}\left(\mathrm{CO}_{2}\right)$ partial pressure. Similar trends were observed to those in water.

The dependence of the final formic acid concentration and the reaction rate as function of temperature was determined in DMSO (Fig. 6, Supplementary Fig. 5 and Supplementary Table 7). Similar to the aqueous system, the final formic acid concentration increases as the temperature decreases, whereas the reaction rate increases with increasing temperature.

The catalyst, $\left[\mathrm{RuCl}_{2}(\mathrm{PTA})_{4}\right]$, was recycled and reused several times (Table 3) without any decrease of activity observed, resulting in a total turn over number (TON) of 749 after four recycles and indicating that considerably higher TONs may be achieved.

Mechanistic studies with $\left[\mathrm{RuCl}_{2}(\mathrm{PTA})_{4}\right]$ catalyst. Moreover, possible catalytic intermediates were identified under catalytic conditions using medium pressure sapphire tubes, by nuclear magnetic resonance (NMR) spectroscopy. The $\left[\mathrm{RuCl}_{2}(\mathrm{PTA})_{4}\right]$

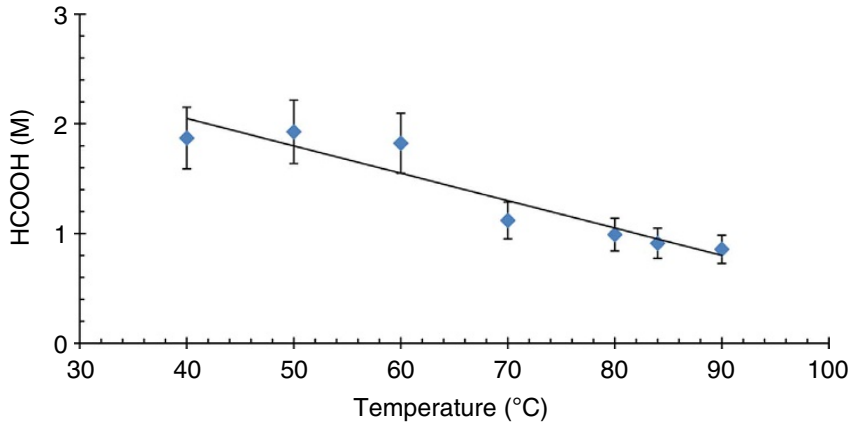

Figure 6 | The influence of temperature on the hydrogenation of $\mathrm{CO}_{2}$ to formic acid using $\left[\mathrm{RuCl}_{\mathbf{2}}(\mathrm{PTA})_{4}\right]$ in DMSO. Conditions: the catalyst was dissolved in $2 \mathrm{ml} \mathrm{DMSO}\left(\left[\mathrm{RuCl}_{2}(\mathrm{PTA})_{4}\right]=2.76 \mathrm{mM}\right)$ under $\mathrm{N}_{2}$ atmosphere. This solution was pressurized at room temperature with $\mathrm{CO}_{2}$ (50 bar) and completed with $\mathrm{H}_{2}$ to 200 bar $\left(P\left(\mathrm{H}_{2}\right) / P\left(\mathrm{CO}_{2}\right)=3\right.$ ). The system was heated to the desired temperature and stirred until the equilibrium of the reaction was reached. The final yield of formic acid was determined by ${ }^{1} \mathrm{H}$ NMR spectroscopy with DSS as an internal standard. The trend line is shown as a guide and is not a mathematical fit of the data. The values are averaged from three to six measurements with a reproducibility of $\pm 15 \%$.

catalyst, both in water and in DMSO- $\mathrm{d}_{6}$, together with DSS $(4,4$ dimethyl-4-silapentane-1-sulphonic acid) as an internal standard, was pressurized to 100 bar with a $P\left(\mathrm{H}_{2}\right) / P\left(\mathrm{CO}_{2}\right)$ pressure ratio of 1 and heated at $50{ }^{\circ} \mathrm{C}$. The hydride region of the resulting ${ }^{1} \mathrm{H}$ NMR spectra reveals the presence of monohydride and dihydride species, that is, $\left[\mathrm{RuH}_{2}(\mathrm{PTA})_{4}\right]$ and $\left[\mathrm{RuH}(\mathrm{PTA})_{4} \mathrm{Cl}\right]$, assigned from a multiplet at -11.2 p.p.m. and a doublet of quartets at -9.2 p.p.m., previously observed in aqueous solution (Supplementary Fig. 6) ${ }^{37}$. In the ${ }^{1} \mathrm{H}\left\{{ }^{31} \mathrm{P}\right\}$ NMR spectra, the two hydride signals were shown to collapse into singlet resonances (Supplementary Fig. 7). On the basis of these observations and prior literature ${ }^{18,37}$, a tentative catalytic cycle can be proposed (Fig. 7).

\section{Discussion}

The $\left[\mathrm{RuCl}_{2}(\mathrm{PTA})_{4}\right]$ complex catalyses the direct hydrogenation of $\mathrm{CO}_{2}$ in DMSO to afford formic acid at unprecedentedly high concentrations, that is, $1.9 \mathrm{M}$ ( $\sim 15 \%$ in volume). Importantly, the catalyst operates in the absence of base (or any other additives) and is highly stable and can be recycled and reused without loss of activity. As demand for formic acid continues to grow, notably as a potential hydrogen carrier $(\mathrm{HCOOH}$ can 
Table 3 | Recyclability of $\left[\mathrm{RuCl}_{2}(\mathrm{PTA})_{4}\right]$ the carbon dioxide hydrogenation in DMSO.

\begin{tabular}{lcc} 
Cycle & HCOOH (M) & TON \\
\hline 1 & 1.8 & 176 \\
2 & 2.1 & 206 \\
3 & 1.8 & 557 \\
4 & 1.9 & 749 \\
\hline
\end{tabular}

$\left[\mathrm{RuCl}_{2}(\mathrm{PTA})_{4}\right](2.76 \mathrm{mM})$ was dissolved in DMSO $(2 \mathrm{ml})$ under $\mathrm{N}_{2}$ atmosphere. The system was pressurized at room temperature to 50 bar with $\mathrm{CO}_{2}$ and completed with 50 bar $\mathrm{H}_{2}$. The system was heated at $60^{\circ} \mathrm{C}$ and stirred for $120 \mathrm{~h}$ until equilibrium of the reaction was reached, average values of several (two to three) measurements are reported with a reproducibility of $\pm 15 \%$.<smiles>[AlH2]=NN1CN2CN3CN(C2)C31</smiles>

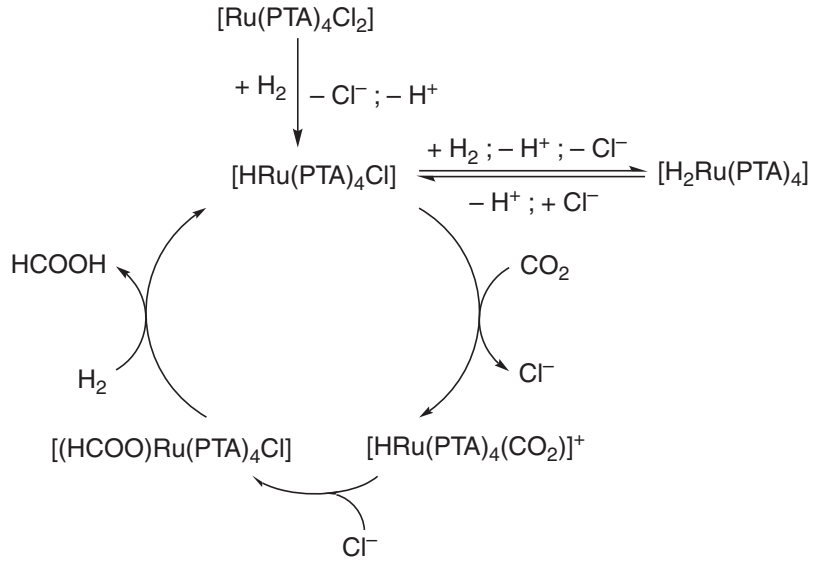

Figure 7 | Catalytic cycle. Proposed catalytic cycle for the hydrogenation of carbon dioxide using $\left[\mathrm{RuCl}_{2}(\mathrm{PTA})_{4}\right]$ in water or DMSO.

selectively decompose into $\mathrm{H}_{2}$ and $\mathrm{CO}_{2}$, Supplementary Figs 8 and 9) ${ }^{38-40}$; viable catalytic processes that directly convert $\mathrm{CO}_{2}$ into formic acid, such as the one described herein may help to propel a hydrogen-based economy.

\section{Methods}

General considerations. $\mathrm{NaHCO}_{3}, \mathrm{NaOH}, \mathrm{HCl}, \mathrm{HCOOH}$ and sodium 3-(trimethylsilyl)-1-propanesulfonate (DSS) were purchased from Fluka, BASF or Merck. $\mathrm{H}_{2}(99.95 \%)$ and $\mathrm{CO}_{2}(99.9 \%)$ were acquired from Carbagas-CH, enriched ${ }^{13} \mathrm{CO}_{2}$ $\left(99 \%\right.$ in $\left.{ }^{13} \mathrm{C}\right)$ was obtained from Cambridge Isotope Laboratories. Double distilled water, DMSO (Sigma-Aldrich), methanol (Fluka), ethanol (Fluka), acetonitrile (Merck), propylene carbonate (Acros), toluene (Merk), ionic liquids [BMIM] $\left[\mathrm{BF}_{4}\right]$ and [BMIM] [tos] (Fluka) were used as solvents. Ligands PTA, TPPTS and TPPMS were purchased from $\mathrm{ABCR}$ and Fluka, respectively. The ligand MePTA and the complexes $\left[\mathrm{RuCl}_{2}(\mathrm{PTA})_{4}\right],\left[\mathrm{RhCl}(\mathrm{TPPMS})_{3}\right],\left[\mathrm{RuCl}_{2}(\mathrm{PTA})\left([9] \mathrm{aneS}_{3}\right)\right]$, $\left.\left[\mathrm{Ru}\left(\mathrm{H}_{2} \mathrm{O}\right)_{4}(\mathrm{MePTA})_{2}\right](\text { tos })_{4},\left[\mathrm{RuCl}_{2} \text { (TPPMS }\right)_{2}\right],\left[\mathrm{RuCl}_{2}(\mathrm{TPPTS})_{2}\right]_{2}$ and $\left[\mathrm{RuCl}_{2}\right.$ (p-cymene) $]_{2}$ were synthesized according to the literature ${ }^{41-50}$

All manipulations were carried out under oxygen-free conditions with degassed solvents, using Schlenk line techniques with $\mathrm{N}_{2}$ as a protective gas. The reactions were carried out in medium pressure sapphire NMR tubes up to 100 bar and were followed by ${ }^{1} \mathrm{H}$ and ${ }^{13} \mathrm{C}$ NMR spectroscopy. At higher pressures Parr autoclaves $(25 \mathrm{ml}, \mathrm{SS} 316)$ were used. NMR spectra were recorded on a Bruker DRX 400 NMR spectrometer and the spectra were fitted with the program WIN-NMR. Formic acid concentrations were determined by quantitative ${ }^{1} \mathrm{H}$ and ${ }^{13} \mathrm{C} \mathrm{NMR}$, by ion chromatography using an ICS-90 system and by HPLC with an Agilent 1260 Infinity instrument.

Homogeneous catalytic hydrogenation reactions. Preliminary studies with different catalysts were performed in a multi-autoclave (HEL CAT 7) by preparing a $2.76 \times 10^{-3} \mathrm{M}(2.76 \mathrm{mM})$ solution of the corresponding catalyst in degassed water $(2 \mathrm{ml})$. The solutions were then pressurized up to 30 bars of $\mathrm{CO}_{2}$ and then completed up to 60 bars with $\mathrm{H}_{2}$ (partial $\mathrm{H}_{2}$ pressure $=30$ bar). The system was heated to $60^{\circ} \mathrm{C}$ and stirred until the reaction was completed. Formic acid yields were determined by ${ }^{1} \mathrm{H}$ NMR spectroscopy using DSS as an external standard $(c=0.0130 \mathrm{M})$, and were verified by ionic chromatography and by HPLC.
For kinetic measurements, catalysts were dissolved in degassed solvents $(2 \mathrm{ml})$ which were introduced into a sapphire NMR tube or into an autoclave under $\mathrm{N}_{2}$ atmosphere. The solutions were pressurized up to 20-55 bars with $\mathrm{CO}_{2}$ and then completed to $60-200$ bar with $\mathrm{H}_{2}$. The system was heated to the required temperature $\left(23-135^{\circ} \mathrm{C}\right)$ and shaken/stirred. In the sapphire NMR tubes, the evolution of $[\mathrm{HCOOH}]$ and $\left[\mathrm{CO}_{2}\right]$ was followed by quantitative ${ }^{1} \mathrm{H}$ or ${ }^{13} \mathrm{C} \mathrm{NMR}$ spectroscopy with DSS as an internal standard ${ }^{51}$. For the autoclaves the yield of formic acid was determined by ${ }^{1} \mathrm{H}$ NMR measurement in the final solution, with DSS as external standard (solution of $0.0130 \mathrm{M}$ ), and controlled by ionic chromatography and by HPLC. During the studies using different organic solvents (in which DSS is insoluble), the final formic acid concentrations were determined by ${ }^{1} \mathrm{H}$ NMR using the standard addition method (with a known $[\mathrm{HCOOH}]$ solution), and controlled by ionic chromatography and by HPLC.

The dissolved $\mathrm{CO}_{2}$ and $\mathrm{H}_{2}$ concentrations were monitored by ${ }^{13} \mathrm{C}$ and ${ }^{1} \mathrm{H} \mathrm{NMR}$ during the catalytic hydrogenation reactions using medium pressure sapphire NMR tubes ${ }^{52,53}$, and display distinct gas and liquid phases under the reaction conditions.

Recycling experiments. Catalyst recycling experiments were performed using $10 \mathrm{mM}\left[\mathrm{RuCl}_{2}(\mathrm{PTA})_{4}\right]$ solutions in water or in DMSO, with a pressure $P($ total $)=100$ bar, $P\left(\mathrm{H}_{2}\right) / P\left(\mathrm{CO}_{2}\right)$ ratio of $1, t=60^{\circ} \mathrm{C}$. Once the reaction reached equilibrium, the systems were depressurized, and the formic acid concentrations were determined. The solvent and the formic acid were removed under vacuum and the remaining solid catalyst was dissolved in the appropriate solvent $\left(\mathrm{H}_{2} \mathrm{O}\right.$ or DMSO), pressurized to 100 bar, $P\left(\mathrm{H}_{2}\right) / P\left(\mathrm{CO}_{2}\right)$ ratio of 1 . After each reaction, the formic acid concentration was determined by ${ }^{1} \mathrm{H}$ NMR spectroscopy and the recycling procedure was repeated. In addition, the resulting formic acid could be dehydrogenated into hydrogen and carbon dioxide using an immobilized catalyst described previously ${ }^{40}$.

\section{References}

1. Mauna Loa Observatory, Hawaii http://co2now.org/ (2014).

2. Tollefson, J. Growing agricultural benefits for climate. Nature 462, 966-967 (2009).

3. Aresta, M. Carbon Dioxide Recovery and Utilization (Kluwer Academic Publishers, Dordrecht, 2010). 
4. Metz, B., Davidson, O., De Coninck, H., Loos, M. \& Meyer, L. Carbon Dioxide Capture and Storage (Cambridge University Press, Cambridge UK, 2005).

5. Dzubak, A. L. et al. L. Ab initio carbon capture in open-site metal-organic frameworks. Nat. Chem. 4, 810-816 (2012).

6. Lin, L.-C. et al. In silico screening of carbon-capture materials. Nat. Mater 11, 633-641 (2012).

7. Balaraman, E., Gunanathan, C., Zhang, J., Shimon, L. J. W. \& Milstein, D. Efficient hydrogenation of organic carbonates, carbamates and formates indicates alternative routes to methanol based on $\mathrm{CO}_{2}$ and CO. Nat. Chem. 3, 609-614 (2011).

8. Centi, G. \& Perathoner, S. Opportunities and prospects in the chemical recycling of carbon dioxide to fuels. Catal. Today 148, 191-205 (2009).

9. Carbon Recycling International http://cri.is/ (2013).

10. Aresta, M. \& Dibenedetto, A. Utilisation of $\mathrm{CO}_{2}$ as a chemical feedstock: opportunities and challenges. Dalton Trans. 2975-2992 (2007).

11. Schlapbach, L. \& Züttel, A. Hydrogen-storage materials for mobile applications. Nature 414, 353-358 (2001).

12. Dalebrook, A. F., Gan, W., Grasemann, M., Moret, S. \& Laurenczy, G. Hydrogen storage: beyond conventional methods. Chem. Commun. 49, 8735-8751 (2013).

13. Enthaler, S., von Langermann, J. \& Schmidt, T. Carbon dioxide and formic acid-the couple for environmental-friendly hydrogen storage? Energy Environ. Sci. 3, 1207-1217 (2010).

14. Joo, F. Breakthroughs in Hydrogen Storage-Formic Acid as a Sustainable Storage Material for Hydrogen. ChemSusChem 1, 805-808 (2008).

15. Grasemann, M. \& Laurenczy, G. Formic acid as a hydrogen source recent developments and future trends. Energy Environ. Sci. 5, 8171-8181 (2012).

16. Barnard, J. H., Wang, C., Berry, N. G. \& Xiao, J. L. Long-range metal-ligand bifunctional catalysis: cyclometallated iridium catalysts for the mild and rapid dehydrogenation of formic acid. Chem. Sci. 4, 1234-1244 (2013).

17. Boddien, A. et al. Efficient dehydrogenation of formic acid using an iron catalyst. Science 333, 1733-1736 (2011).

18. Federsel, C., Jackstell, R. \& Beller, M. State-of-the-art catalysts for hydrogenation of carbon dioxide. Angew. Chem. Int. Ed. 49, 6254-6257 (2010).

19. Jessop, P. G., Joo, F. \& Tai, C. C. Recent advances in the homogeneous hydrogenation of carbon dioxide. Coord. Chem. Rev. 248, 2425-2442 (2004)

20. Jessop, P. G., Ikariya, T. \& Noyori, R. Homogeneous catalytic hydrogenation of supercritical carbon dioxide. Nature 368, 231-233 (1994).

21. Leitner, W. Carbon dioxide as a raw material the synthesis of formic acid and its derivatives from $\mathrm{CO}_{2}$. Angew. Chem. Int. Ed. 34, 2207-2221 (1995).

22. Jessop, P. G. in Handbook of Homogeneous Hydrogenation 489-511 (Wiley-VCH, Weinheim, 2007).

23. Tanaka, R., Yamashita, M. \& Nozaki, K. Catalytic hydrogenation of carbon dioxide using $\operatorname{Ir}(\mathrm{III})$-pincer complexes. J. Am. Chem. Soc. 131, 14168-14169 (2009).

24. Papp, G., Csorba, J., Laurenczy, G. \& Joó, F. A charge/discharge device for chemical hydrogen storage and generation. Angew. Chem. Int. Ed. 50, 10433-10435 (2011).

25. Hull, J. F. et al. Reversible hydrogen storage using $\mathrm{CO}_{2}$ and a proton-switchable iridium catalyst in aqueous media under mild temperatures and pressures. Nat. Chem. 4, 383-388 (2012).

26. Boddien, A. et al. Towards the development of a hydrogen battery. Energy Environ. Sci. 5, 8907-8911 (2012).

27. Laurenczy, G., Joo, F. \& Nadasdi, L. Formation and characterization of watersoluble hydrido-ruthenium(II) complexes of 1,3,5-triaza-7phosphaadamantane and their catalytic activity in hydrogenation of $\mathrm{CO}_{2}$ and $\mathrm{HCO}_{3}^{-}$in aqueous solution. Inorg. Chem. 39, 5083-5088 (2000).

28. Preti, D., Squarcialupi, S. \& Fachinetti, G. Production of $\mathrm{HCOOH} / \mathrm{NEt}_{3}$ adducts by $\mathrm{CO}_{2} / \mathrm{H}_{2}$ incorporation into neat $\mathrm{NEt}_{3}$. Angew. Chem. Int. Ed. 49, 2581-2584 (2010).

29. Tai, C. C., Chang, T., Roller, B. \& Jessop, P. G. High-pressure combinatorial screening of homogeneous catalysts: hydrogenation of carbon dioxide. Inorg. Chem. 42, 7340-7341 (2003).

30. Schaub, T. \& Paciello, R. A. A process for the synthesis of formic acid by $\mathrm{CO}_{2}$ hydrogenation: thermodynamic aspects and the role of CO. Angew. Chem. Int. Ed. 50, 7278-7282 (2011).

31. Zhao, G. Y. \& Joo, F. Free formic acid by hydrogenation of carbon dioxide in sodium formate solutions. Catal. Commun. 14, 74-76 (2011).

32. Joszai, I. \& Joo, F. Hydrogenation of aqueous mixtures of calcium carbonate and carbon dioxide using a water-soluble rhodium(I)-tertiary phosphine complex catalyst. J. Mol. Catal. A Chem. 224, 87-91 (2004).

33. Graf, E. \& Leitner, W. Direct formation of formic acid from carbon dioxide and dihydrogen using the $\left[\{\mathrm{Rh}(\operatorname{cod}) \mathrm{Cl}\}_{2}\right]-\mathrm{Ph}_{2} \mathrm{P}\left(\mathrm{CH}_{2}\right)_{4} \mathrm{PPh}_{2}$ catalyst system. J. Chem. Soc. Chem. Commun. 623-624 (1992).

34. Ogo, S., Hayashi, H. \& Fukuzumi, S. Aqueous hydrogenation of carbon dioxide catalysed by water-soluble ruthenium aqua complexes under acidic conditions. Chem. Commun. 2714-2715 (2004).
35. Ogo, S., Kabe, R., Hayashi, H., Harada, R. \& Fukuzumi, S. Mechanistic investigation of $\mathrm{CO}_{2}$ hydrogenation by $\mathrm{Ru}(\mathrm{II})$ and $\mathrm{Ir}(\mathrm{III})$ aqua complexes under acidic conditions: two catalytic systems differing in the nature of the rate determining step. Dalton Trans. 4657-4663 (2006).

36. Wesselbaum, S., Hintermair, U. \& Leitner, W. Continuous-flow hydrogenation of carbon dioxide to pure formic acid using an integrated $\mathrm{scCO}_{2}$ process with immobilized catalyst and base. Angew. Chem. Int. Ed. 51, 8585-8588 (2012).

37. Laurenczy, G., Jedner, S., Alessio, E. \& Dyson, P. J. In situ NMR characterisation of an intermediate in the catalytic hydrogenation of $\mathrm{CO}_{2}$ and $\mathrm{HCO}_{3}^{-}$in aqueous solution. Inorg. Chem. Commun. 10, 558-562 (2007).

38. Fellay, C., Dyson, P. J. \& Laurenczy, G. A viable hydrogen-storage system based on selective formic acid decomposition with a ruthenium catalyst. Angew. Chem. Int. Ed. 47, 3966-3968 (2008).

39. Fellay, C., Yan, N., Dyson, P. J. \& Laurenczy, G. Selective formic acid decomposition for high-pressure hydrogen generation: a mechanistic study. Chem. Eur. J. 15, 3752-3760 (2009).

40. Gan, W., Dyson, P. J. \& Laurenczy, G. Heterogeneous silica-supported ruthenium phosphine catalysts for selective formic acid decomposition. ChemCatChem 5, 3124-3130 (2013).

41. Daigle, D. J., Pepperman, A. B. \& Vail, S. L. Synthesis of a monophosphorus analog of hexamethylenetetramine. J. Heterocycl. Chem. 11, 407-408 (1974).

42. Daigle, D. J. \& Pepperman, A. B. Chemical proof for preferred nitrogen quarternization in 1,3,5-triaza-7-phosphaadamantane. J. Heterocycl. Chem. 12, 579-580 (1975).

43. Darensbourg, D. J. et al. Water-soluble organometallic compounds 4 . Catalytic-hydrogenation of aldehydes in an aqueous two-phase solvent system using a 1,3,5-triaza-7-phosphaadamantane complex of ruthenium. Inorg. Chem. 33, 200-208 (1994).

44. Darensbourg, D. J., Joo, F., Kannisto, M., Katho, A. \& Reibenspies, J. H. Water-soluble organometallic compounds.2. catalytic-hydrogenation of aldehydes and olefins by new water-soluble 1,3,5-triaza-7-phosphaadamantane complexes of ruthenium and rhodium. Organometallics 11, 1991-1993 (1992).

45. Joó, F. et al. (Meta-sulfonatophenyl)diphenylphosphine, sodium salt and its complexes with rhodium(I), ruthenium(II), iridium(I). Inorg. Synth. 32, 1-8 (1998).

46. Serli, B. et al. Is the aromatic fragment of piano-stool ruthenium compounds an essential feature for anticancer activity? The development of new RuII-[9] $\mathrm{aneS}_{3}$ analogues. Eur. J. Inorg. Chem. 3423-3434 (2005).

47. Bennett, M. A. \& Smith, A. K. Arene ruthenium(II) complexes formed by dehydrogenation of cyclohexadienes with ruthenium(III) trichloride. J. Chem. Soc. Dalton 233-241 (1974).

48. Gandolfi, C., Heckenroth, M., Neels, A., Laurenczy, G. \& Albrecht, M. Chelating NHC ruthenium(II) complexes as robust homogeneous hydrogenation catalysts. Organometallics 28, 5112-5121 (2009).

49. Pruchnik, F. P., Smoleński, P., Galdecka, E. \& Galdecki, Z. Structural, spectroscopic and catalytic properties of water-soluble hydride rhodium complexes $\left[\mathrm{RhH}\left(\mathrm{Rtpa}^{+} \mathrm{I}^{-}\right)_{4}\right] \mathrm{H}_{2} \mathrm{O}(\mathrm{R}=\mathrm{Me}, \mathrm{Et})$. Inorg. Chim. Acta 293, 110-114 (1999).

50. Kovacs, J., Joo, F., Benyei, A. C. \& Laurenczy, G. Reactions of $\left[\mathrm{Ru}\left(\mathrm{H}_{2} \mathrm{O}\right)_{6}\right]^{2+}$ with water-soluble tertiary phosphines. Dalton Trans. 2336-2340 (2004).

51. Moret, S., Dyson, P. J. \& Laurenczy, G. Direct, in situ determination of $\mathrm{pH}$ and solute concentrations in formic acid dehydrogenation and $\mathrm{CO}_{2}$ hydrogenation in pressurised aqueous solutions using ${ }^{1} \mathrm{H}$ and ${ }^{13} \mathrm{C}$ NMR spectroscopy. Dalton Trans. 42, 4353-4356 (2013).

52. Symons, E. A. Hydrogen gas solubility in the dimethylsulfoxide - water system: a further clue to solvent structure in these media. Can. J. Chem. 49, 3940-3947 (1971).

53. Dyson, P. J., Laurenczy, G., Ohlin, C. A., Vallance, J. \& Welton, T. Determination of hydrogen concentration in ionic liquids and the effect (or lack of) on rates of hydrogenation. Chem. Commun. 2418-2419 (2003).

\section{Acknowledgements}

Swiss National Science Foundation, EOS Holding and EPFL are thanked for financial support.

\section{Author contributions}

S.M. carried out the syntheses and the kinetic measurements; P.J.D. was involved in scientific discussions; G.L. designed and directed the project, supervised the research work; S.M., P.J.D. and G.L. participated in the preparation of the manuscript.

\section{Additional information}

Supplementary Information accompanies this paper at http://www.nature.com/ naturecommunications 
Competing financial interests: A patent has been filed (PCT/IB2014/058883). The authors declare no competing financial interests

Reprints and permission information is available online at http://npg.nature.com/ reprintsandpermissions/

How to cite this article: Moret, S. et al. Direct synthesis of formic acid from carbon dioxide by hydrogenation in acidic media. Nat. Commun. 5:4017 doi: 10.1038/ ncomms5017 (2014). (c) (1) (2) This work is licensed under a Creative Commons AttributionNonCommercial-ShareAlike 3.0 Unported License. The images or other third party material in this article are included in the article's Creative Commons license, unless indicated otherwise in the credit line; if the material is not included under the Creative Commons license, users will need to obtain permission from the license holder to reproduce the material. To view a copy of this license, visit http:// creativecommons.org/licenses/by-nc-sa/3.0/ 